\title{
TRANSACTIONS of the AMERICAN FISHERIES SOCIETY
}

\section{The Forgotten Requirement for Age Validation in Fisheries Biology}

\author{
R. J. Beamish and G. A. McFarlane \\ Department of Fisheries and Oceans, Fisheries Research Branch \\ Pacific Biological Station, Nanaimo, British Columbia V9R $5 \mathrm{~K} 6$
}

\begin{abstract}
A survey of 500 studies published between 1907 and 1980 that included estimates of fish age indicated that only $65 \%$ mentioned age validation or attempted to validate the ageing technique. In less than $3 \%$ was the technique validated for all age classes. Among the $35 \%$ that did not consider age validation, many did not consider the possibility that ages may be incorrect. Among 75 additional publications published in primary journals between 1965 and 1980 that assessed stock dynamics and used fish ages, only $40 \%$ mentioned or attempted age validation, and none successfully validated all age groups used in the analysis. Many investigators continue to neglect the critical study of age validation despite the clear direction of the early work on age determination. We show that estimated ages greater than the maximum validated age must not be considered accurate. Use of inaccurate ages has caused serious errors in the management and understanding of fish populations. Only by mark-recapture studies or use of known-age fish can all age classes in a population be validated. If such studies are not possible, fish should be aged by several methods, and the possibility of errors in age estimates must be considered.
\end{abstract}

Received April 5, 1983

Accepted August 9, 1983

Pioneer work on the determination of fish ages stressed the importance of proving that a technique was valid (Van Oosten 1923, 1929, 1941; Hile 1936). In 1941, Van Oosten stated that fisheries investigators had "woefully neglected" to evaluate the scale method of age determination. He felt that this method of age determination had been taken "too much for granted in the belief that it is a simple one which can be applied without technical knowledge." He stressed that the validity of a method must be established for each species of fish studied: "It is a sad commentary on the attitude of our investigators that although age determinations of at least 60 freshwater species have been published by more than 80 authors in more than 150 papers, in only some half dozen publications did the authors attempt to evaluate critically the scale method."

All ages for each species must be validated. Extrapolation beyond the maximum age validated, between species, or sometimes between other populations of the same species is dangerous. Validating a method of age determination is as important in fisheries biology as standardizing solutions or calibrating instruments are in other sciences.

We believe the requirement to validate age determinations continues to be neglected. To examine this, we reviewed 500 papers that use age estimates derived from several techniques. The consequences of not validating ages are illustrated for a common freshwater species, the white sucker Catostomus commersoni, and an important marine species, the Pacific ocean perch Sebastes alutus.

Terminology must be standardized. Validation means proving a technique is accurate. Accuracy can be proven or estimated; estimates of accuracy are less valuable, but in some cases only an estimate is possible. Precision relates to reproducibility and is not a measure of accuracy. The degree of agreement among readers is a measure of the precision of the determi- 
TABLE 1.-Number of attempts to validate methods of age determinations from 500 publications that included age estimates for fish.

\begin{tabular}{|c|c|c|c|c|}
\hline \multirow[b]{2}{*}{$\begin{array}{l}\text { Degree of } \\
\text { validation }\end{array}$} & \multicolumn{3}{|c|}{ Publication date } & \multirow[b]{2}{*}{ Total } \\
\hline & $\begin{array}{l}\text { Pre- } \\
1940\end{array}$ & $\begin{array}{c}1940- \\
1969\end{array}$ & $\begin{array}{r}1970- \\
1980\end{array}$ & \\
\hline No validation attempted & 41 & 80 & 49 & 170 \\
\hline Validation attempted & 44 & 156 & 130 & 330 \\
\hline $\begin{array}{l}\text { Validation of first few } \\
\text { age groups only }\end{array}$ & 42 & 125 & 109 & 276 \\
\hline Validation of all age groups & 2 & 31 & 21 & 54 \\
\hline Validation successful & 1 & 11 & 5 & 17 \\
\hline
\end{tabular}

nations and not the accuracy of the technique. An annulus, identified directly or indirectly, is any zone, mark, or pattern of growth that forms once a year (Chugunova 1959; Ricker 1968). Thus, by definition, only one annulus can form in a year. These are the key terms relevant to this report. Other terms have been defined elsewhere (for example, Chugunova 1959).

\section{Literature Survey}

A survey of 500 studies that involved the ageing of fish was undertaken to determine how often, and to what extent, age-determination methods were validated. Studies included in the review were published between 1907 and 1980 in scientific journals from several countries, the majority $(60 \%)$ having been published in North America. The papers were reviewed without selection and the number of papers related only to the effort available. We doubt if increasing the sample size would alter any conclusions. In addition, we nonselectively reviewed 75 studies in which age estimates were used specifically for analyses of stock dynamics. These were published in five major journals during 1965-1980. A list of all reviewed papers is available from the authors.

For each paper it was determined if validation was attempted or mentioned. Validation was considered successful when all reported ages were validated; that is, there were no ages reported that were older than the oldest validated age. For studies in which validation was attempted, separation was made between validation techniques that were capable of validating ages for all age groups and methods that apply only to the period of initial faster growth. The former group includes mark-recapture techniques and capture of known-age fish. The latter group includes an analysis of length-frequency modes, monitoring of strong year classes, examination of the edge of a structure, comparison of back-calculated lengths with observed lengths of the corresponding age group, growth analysis, and comparisons among different techniques. The maximum age validated was identified as well as the age range. It was determined if precision was estimated and if precision was used to infer that the technique was accurate. The studies were separated into three periods: pre-1940, 1940-1969, 1970 1980 .

No age validation was attempted in $35 \%$ of the 500 studies (Table 1). Most attempts at validation involved only the first 1 or 2 years. In 54 studies $(9 \%)$, the technique used was applicable to all age groups, but in only $17(3 \%)$ were all age groups in the population actually validated. In almost all cases, validation of the first few years was considered or implied to validate for all age groups; that is, validation was extrapolated beyond the oldest validated age. Authors of 29 papers compared more than one structure. For 101 studies, it could be interpreted that precision was used to imply accuracy.

Validation was considered in an increasing percentage of studies in recent years; however, the fraction of studies that involved techniques apable of validating all age groups did not change in the two periods from 1940 to 1980. Some authors (27) referred to previous studies for validation of their techniques; of these, seven referred to studies of Hile or Van Oosten although both these authors stated that an agedetermination technique should be validated for populations as well as for species.

Of the 75 papers that dealt with stock dynamics, $40 \%$ mentioned or attempted validation. Of these, none validated ages for all age groups used in the analysis. It is surprising, perhaps even shocking, that $60 \%$ of these studies did not consider the consequences of errors in age determination. A small percentage $(8 \%)$ evaluated the precision of the age estimates.

The applicability of validation techniques in some of the studies in our review, or the relative success of some validation attempts, may be subject to different interpretations. However, such differences in interpretation will not alter the overwhelming conclusion that fisheries biologists seldom have successfully validated methods used to age fish despite the clear warnings of early workers (Van Oosten 1923, 1929, 1941; Hile 1936). 


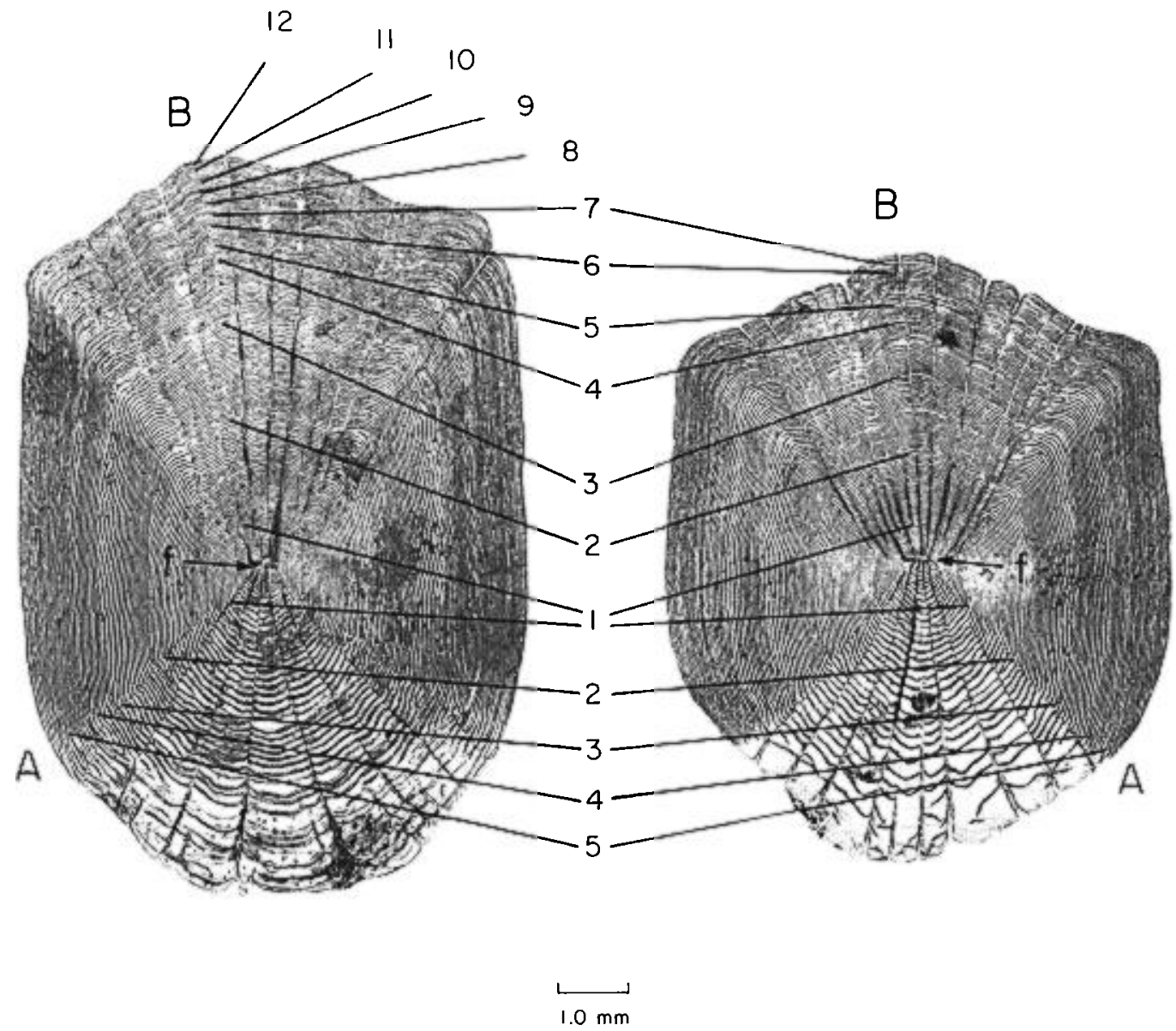

8615

8521

FIGURE 1.-Scales from white suckers tagged at age 5 and recaptured 8 years later. $A=$ boundary of anterior quadrant; $B=$ posterior edge of posterior quadrant; $f=$ focus. At the time of recapture both fish seemed to be age 5 by Spoor's (1939) criteria (axis $f-A$ ). Older ages could be estimalated from irregularities in the posterior quadrant (axis $f-B$ ); although these irregularities produced estimates closer to the known age for fish 8615, they did not do so for fish 8521 .

\section{Importance of Validation}

Some biologists may feel that we are overly rigid in our insistence that successful validation of an age-determination method means that all age groups being considered are validated. Our insistence is based on the consequences of nonvalidation, and we offer two case histories to illustrate the importance of such consequences. In one case, biological understanding of a common freshwater species, white sucker, was impeded for many years because only young ages were validated. In the other case, underestimated ages of Pacific ocean perch may have imposed million-dollar losses on the commercial fishery for that species.

\section{White Suckers}

The scale from the white sucker appears to be a model for the scale method of age determination (Fig. 1 and Spoor 1939). Circuli are distinct and widely spaced during periods of active fish growth; spacing becomes reduced as yearly growth declines. When scale growth resumes in each year, the new circulus forms around the incomplete circuli of the previous year. The annulus is defined as this zone of closely spaced circuli "cut off" by the new circulus, and typically it is measured where the circuli enter the posterior quadrant of the scale. In the anterior quadrant of the scale, the annulus frequently is associated with irregularities in circuli formation. 
Stewart (1926) validated the scale method by following the yearly growth of scales but only for very young white suckers. His application of the scale method showed that fish grew rapidly and that growth increased in the 6th and 7 th years (we believe this increase in growth results from underestimating the age of older fish). Spoor (1939) also validated the scale method for young fish by examining the annual growth on the edge of the scale. The oldest fish in his study was 10 years and $94 \%$ were $3-6$ years old. Eddy and Carlander (1942) examined 2,655 specimens from 69 lakes; the oldest fish reported was 9 years old but the authors attempted no validation because "for practical purposes the scale method of growth determination is recognized as valid." Subsequently, there have been published and unpublished studies in which the scale method was used without validation, the applicability of the scale method was questioned, or scales were shown to be unreliable and less useful for age determination than other structures (Raney and Webster 1942; Rawson 1942; Ovchynnyk 1965; Geen et al. 1966; Coble 1967; Beamish and Harvey 1969; Beamish 1973; Quinn and Ross 1982).

Early studies indicated that white suckers grew relatively quickly to ages $4-7$ years, and that few survived beyond age 9 or 10 . Annual mortality calculated from these ages was high after maturity even though active growth continued. Recent studies that validated and used the finray method (Beamish and Harvey 1969; Beamish, unpublished data) showed that a relatively large number of fish in unexploited populations survive after increases in length cease or become minimal. There is a period of very reduced growth (Beamish 1973) and fish can be much older than previously thought. The oldest age (not validated) for this species is 23 years (Fig. 2) which more than doubles the early estimates of the life span of this species.

Our understanding of white sucker biology changed when fin rays rather than scales were used for age determination. All annuli are distinct on sections of fin rays (Fig. 2) whereas annuli on scales are difficult to identify after about age 5 (Fig. 1). With hindsight afforded by validated ages, irregularities in circuli structure in the posterior quadrant of scales may be interpreted as annuli but they are difficult to define and they may not form every year (Fig. 1).

\section{Pacific Ocean Perch}

The financial costs and management consequences of underestimating the age of older fish can be illustrated for the Pacific ocean perch fishery off the west coast of Canada. Prior to 1980 , fish in the commercial catch were thought to be considerably younger than now believed. Biologists of one of the major foreign nations fishing this species used scales to estimate age (Chikuni and Wakabayashi 1970) and they believed these fish were rapid-growing and relatively short-lived. Use of otolith surfaces by North American scientists (Westrheim 1973) indicated the fish were older than suggested by scales but not as old as now believed by people who have studied otolith sections for this species and other rockfish (Beamish 1979; Archibald et al. 1981; Bennett et al. 1982; Chilton and Beamish 1982; Archibald et al., 1983).

New estimates of age have greatly reduced the estimated rate of natural mortality and produced a more conservative management strategy (Archibald et al. 1981; Archibald et al., 1983). If this strategy had been applied at the beginning of the fishery and some educated guesses made about long-term yields, it can be estimated that lost wholesale value to Canadian industry, in 1981 Canadian dollars, has been about 4 million dollars annually. The total loss in yield for the northeast Pacific would be considerably higher. While it is a little unfair to make this comparison because it is questionable whether or not the early fishery could have been better managed even with our present knowledge, this example suggests the costs and consequences of not knowing that older, slowergrowing fish are an important component of the commercial catch. The use of incorrect growth rates can also lead to rather large errors in estimates of stock production (Ricker 1969).

As demonstrated in these studies, it may be difficult to determine age from some structures after the growth rate changes and growth increments on a structure are reduced. This period of reduced growth often occurs after maturity, can be quite long (Power 1978; Beamish 1979; Beamish and Chilton 1982; Chilton and Beamish 1982), and possibly is important in maintaining populations (Leaman and Beamish, in press). It is illogical to dismiss ageing errors as not being important when the degree of error has not been assessed by validation. 
A

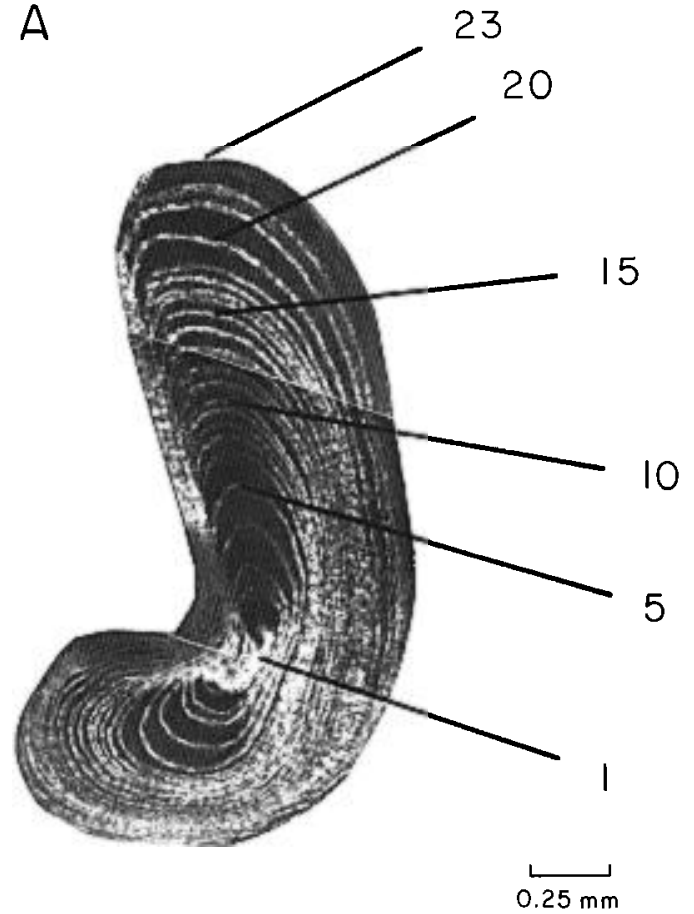

C

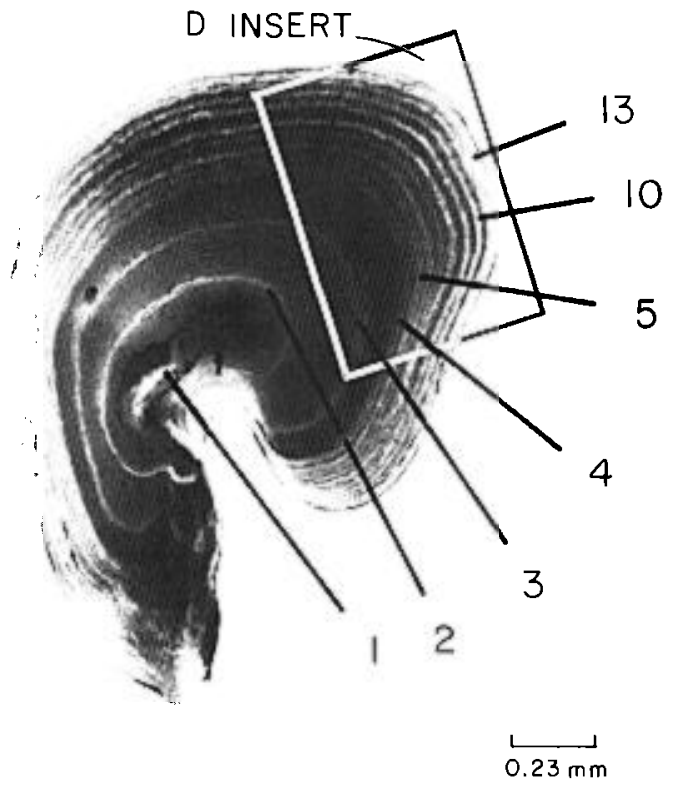

B

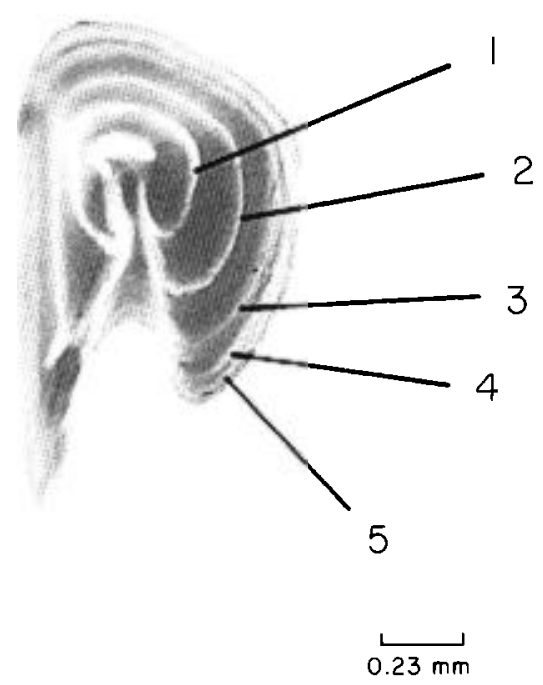

D 5

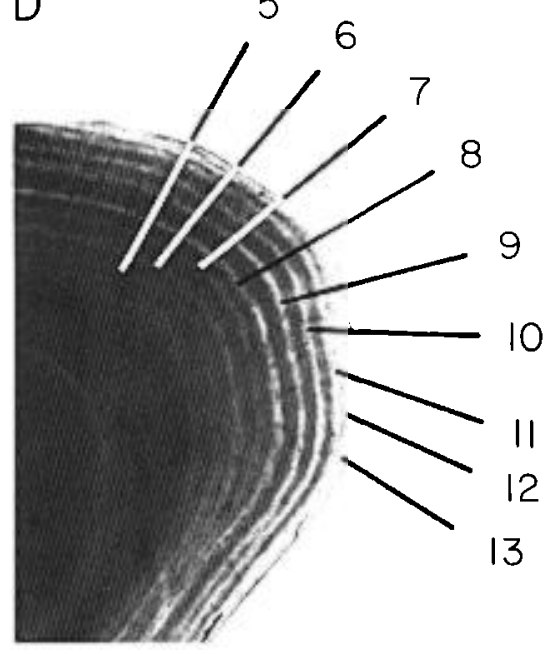

Figure 2.-Pectoral fin-ray sections from white suckers. (A) Fish aged $23+$ years. (B-D) Fish 8615 , aged at $5+$ years at the time of tagging (May 1973)(B) and 13+ years at the time of recapture (June 1981)(C). Insert (D) shows reduction in spacing between the annuli with age. (Sections are from different fin rays, hence their morphologies differ. The whole fin from both sides should have been sampled.) 
A

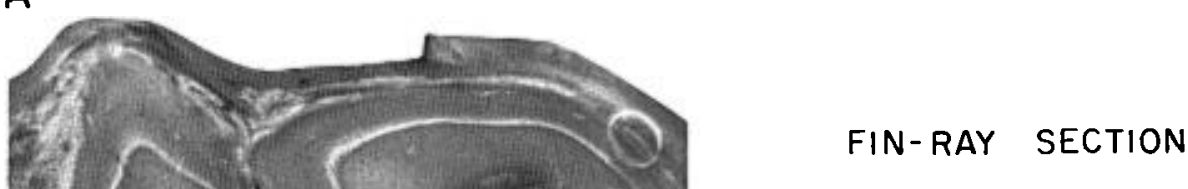

OTC MARK
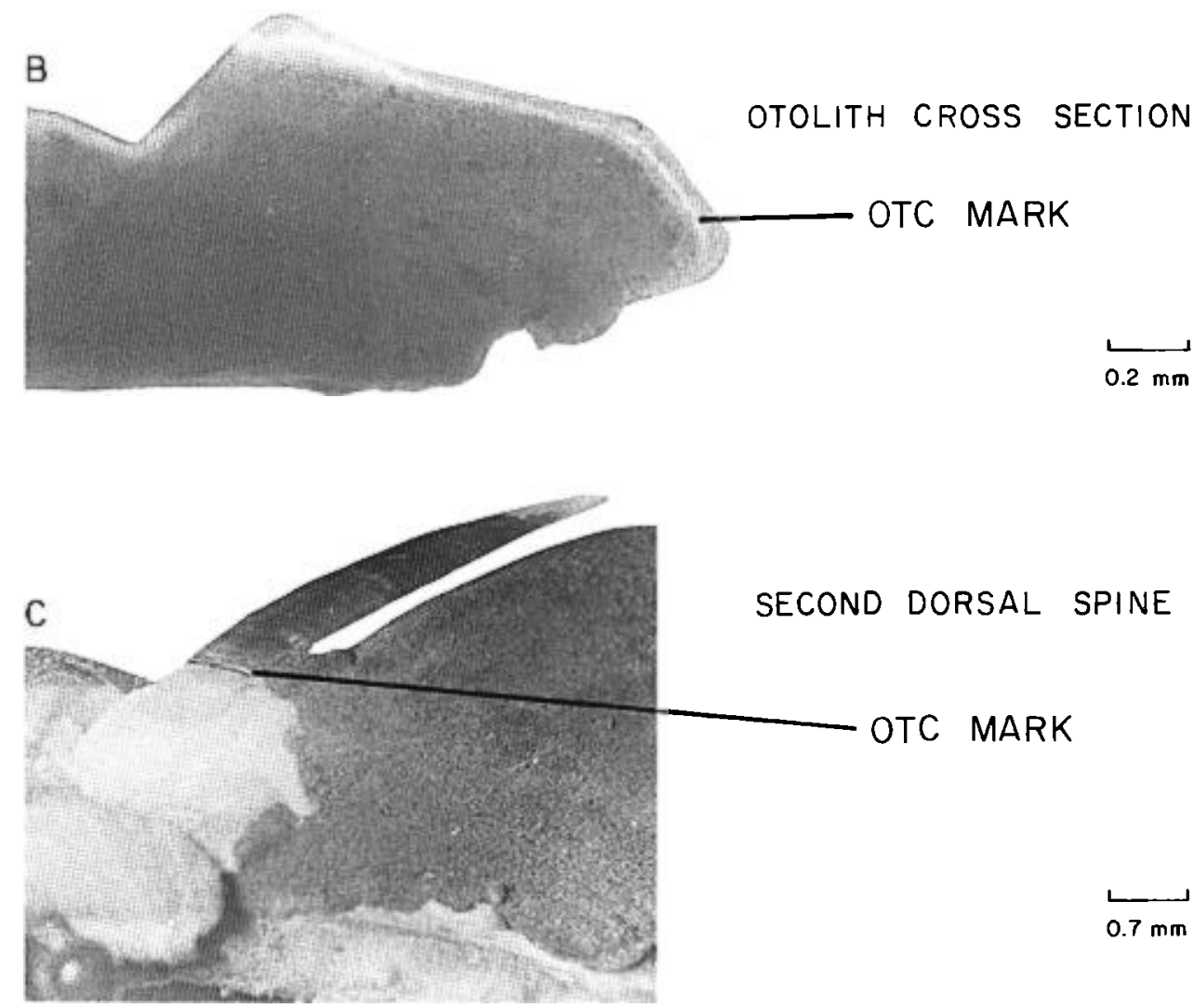

FiGURE 3.-Structures used for age determination that were marked by oxyletracycline (OTC) injections. (A) Fin-ray section from a lingcod Ophiodon elongatus at liberty 2 years after injection. (B) Broken section of an otolith from a sablefish Anoplopoma fimbria at liberty 3 years after injection. (C) Second dorsal spine from a spiny dogfish Squalus acanthias at liberty 1 year after injection. 


\section{Recommended Validation Methods}

The validation of ages of older fish requires either a mark-recapture study or the identifcation of known-age fish in the population. It may be possible to find some "natural" mark on a structure that identifies a particular year class, but such marks appear to be very rare. For most species, at this time, there is little choice but to undertake a mark-recapture study for validation. The disadvantages relate to the technical problems of applying a tag and the time required for growth of the particular structure. However, the study will allow all age groups to be examined.

At the time of tagging, scales or fin rays can be removed for comparison with similar structures upon recapture of the fish. The effect of tagging and removal of structures on growth should be monitored but even if there is some initial effect it probably will not interfere with a validation study. It is also possible to use chemicals to mark structures. Fluorochrome labels are most commonly used, especially when a structure cannot be removed at time of marking. They are readily available, easily administered, and provide a distinct fluorescent mark on a variety of structures when exposed to ultraviolet light (for example, Fig. 3). Appropriate dosages for oxytetracycline are discussed by Beamish et al. (in press).

\section{Conclusions}

In general, the age-determination method selected for many studies probably provides accurate estimates of age over the range of more rapid growth. However, when growth is reduced because of the sex of an individual, maturation, food limitations, changes in behavior, environmental conditions, or other cause, it is possible, even probable, that there will be a change in the appearance of an annulus and that the method of age determination will have to be modified. Only by validating the method can it be proven that fish are not older than estimated and that older fish are not an important component of the population.

If estimates of age of older fish are not validated, it is possible that errors are occurring. Such errors will not be random and will be biased towards younger ages, resulting in an accumulation of estimates in the vicinity of the age at which a particular technique or interpretation breaks down. Mortality estimates then can be overestimated, particularly for males if they grow more slowly than females. The importance of strong year classes also can be masked.

There are other more subtle features of a population that may not be detected if it is not known that older fish exist. Different growth rates among stocks may not be detected. The importance of longevity or the mechanisms by which a particular population survives in its environment may not be considered. Some people may feel that these "ecological" considerations are unimportant or less important for managing a population. However, because populations have had to survive in changing ecosystems for thousands of years, life-history parameters are adaptive. Adaptation is brought about by changes in life-history traits such as age at maturity, rates of growth, the number of annual reproductions, and fecundity. These traits are important and must be clearly understood when the response of a population to the extreme stress placed on it by a commercial fishery is considered. Accurate ages are the key to defining these parameters.

We encourage biologists to re-examine some longstanding beliefs such as the general applicability of the scale method for age determination (Lux 1971; Everhart and Young 1981), or the view that there is close or isometric relationship between size (length) of fish and size of hard parts throughout the life span of the fish (Lagler 1956). We believe that there has been a tendency to forget the need to validate age estimates, and that this may have led to rather serious misunderstandings of the biology and population dynamics of some important commercial species.

Estimates of age are difficult to produce and are not unequivocal. Because they are fundamental to an understanding of the biology of fishes and the dynamics of fish populations it is essential that they be proven accurate.

\section{Acknowledgments}

Claudia Hand and Kathy Best carried out the literature review. Doris Chilton, Shayne MacLellan, and Dawn Barnes assisted in the preparation of figures and the estimation of some ages. Bruce Leaman provided estimates of yields of Pacific ocean perch and reviewed the manuscript. Edward Tripple supplied the data he collected from the three tagged white suckers that were recaptured 8 years after being tagged. The fin used in Fig. 2A was supplied by Barry $\mathrm{Pa}$ quin, Saskatchewan Research Council. 


\section{References}

Archibald, C. P., D. Fournier, and B. M. Leaman. 1983. Reconstruction of stock history and development of rehabilitation strategies for Pacific ocean perch in Queen Charlotte Sound, Canada. North American Journal of Fisheries Management 3:283-294.

Archibald, C. P., W. Shaw, and B. M. Leaman. 1981. Growth and mortality estimates of rockfishes (Scorpaenidae) from B. C. coastal waters, 1977-1979. Canadian Technical Report of Fisheries and Aquatic Sciences 1048.

BeAmish, R.J. 1973. Determination of age and growth of populations of the white sucker (Catostomus commersoni) exhibiting a wide range in size at maturity. Journal of the Fisheries Research Board of Canada 30:607-616.

BeAmish, R. J. 1979. New information on the longevity of Pacific ocean perch (Sebastes alutus). Journal of the Fisheries Research Board of Canada 36:1395-1400.

Bfamish, R. J., and D. E. Chilton. 1982. Preliminary evaluation of a method to determine the age of sablefish (Anoplopoma fimbria). Canadian Journal of Fisheries and Aquatic Sciences 39:277287.

Bfamish, R. J., and H. H. Harvey, 1969. Age determination in the white sucker. Journal of the Fisheries Research Board of Canada 26:633-638.

Beamish, R. J., G. A. McFarlane, and D. E. Chil.ton. In press. Use of oxytetracycline and other methods to validate a method of age determination for sablefish (Anoplopoma fimbria). In Proceedings of the second Lowell Wakefield fisheries symposium. Anchorage, Alaska, USA.

Benne I'T, J. T., G. W. Bofhlekt, and K. K. TukfKIAN. 1982. Confirmation of longevity in Sebastes diploproa (Pisces: Scorpaenidae) using ${ }^{210} \mathrm{~Pb} /{ }^{226} \mathrm{Ra}$ measurements in otoliths. Marine Biology 71:209215.

Chikuni, S., and K. Wakabayashi. 1970. On the scale characters of the Pacific ocean perch in the Bering Sea-1II. Objectivity and accuracy of age determination by scale reading. Bulletin of the Far Seas Fisheries Research Laboratory (Shimizu) 3:205-214.

Chilton, D. E., and R. J. Bfamish. 1982. Age determination methods for fishes'studied by the Groundfish Program at the Pacific Biological Station. Canadian Special Publication of Fisheries and Aquatic Sciences 60 .

Chugunova, N. I. 1959. Age and growth studies in fish. Izvestiya Akademii Nauk SSSR. Translated from Russian: Israel Program for Scientific Translations, 1963, Jerusalem, Israel.

Coble, D. W. 1967. The white sucker population of South Bay, Lake Huron, and effects of the sea lamprey on it. Journal of the Fisheries Research Board of Canada 24:2117-2136.
Eddy, S., And K. D. Carlander. 1942. Growth rate studies of Minnesota fishes. Minnesota Bureau of Fisheries Research Report 28:1-64.

Everhart, W. H., and W. D. Younc. 1981. Principles of fishery science, 2nd edition. Cornell University Press, Ithaca, New York, USA.

Geen, G. H., T. G. Northcole, G. F. Haktman, and C. C. LiNDSFY, 1966. Life histories of two species of catostomid fishes in Sixteen Mile Lake, British Columbia, with particular reference to inlet stream spawning. Journal of the Fisheries Research Board of Canada 23:1761-1788.

Hile, R. 1936. Age and growth of the cisco, Leucichthys artedi (Le Sueur), in the lakes of the Northeastern Highlands, Wisconsin. United States Bureau of Fisheries Bulletin 48:211-317.

LAGLER, K. F. 1956. Freshwater fishery biology, second edition. William C. Brown, Dubuque, Iowa, USA.

Leaman, B. M., and R. J. Beamish. In press. Ecological and management implications of longevity in some northeast Pacific groundfishes. International North Pacific Fisheries Commission Bulletin.

Lux, F. E. 1971. Age determination. United States National Marine Fisheries Service Fishery Leaflet 637, Washington, District of Columbia, USA.

OvCHYNNYK, M. M. 1965. On age determination with scales and bones of the white sucker, Catostomus commersoni (Lacépède). Zoologischer Anzeiger $175: 325-345$.

Powek, G. 1978. Fish population structure in Arctic lakes. Journal of the Fisheries Research Board of Canada 35:53-59.

Quinn, S. P., AND M. R. Ross. 1982. Annulus formation by white suckers and the reliability of pectoral fin rays for ageing them. North American Journal of Fisheries Management 2:204-208.

Raney, E. C., And D. A. Webster. 1942. The spring migration of the common white sucker, Catostomus commersoni (Lacépède), in the Skaneateles Lake inlet, New York. Copeia 1942:139-148.

Rawson, D. S. 1942. A comparison of some large alpine lakes in western Canada. Ecology 23:143161.

RICKER, W. E., editor. 1968. Methods for assessment of fish production in fresh waters. 1BP (International Biological Programme) Handbook 3.

Ricker, W. E. 1969. Effects of size-selection mortality and sampling bias on estimates of growth, mortality, production, and yield. Journal of the Fisheries Research Board of Canada 26:479-541.

Spoor, H. 1939. Age and growth of the sucker, $\mathrm{Ca}$ tostomus commersoni (Lacépède), in Muskellunge Lake, Vilas County, Wisconsin. Transactions of the Wisconsin Academy of Science 31:457-505.

Siewart, N. A. 1926. Development, growth and food habits of the white sucker, Catostomus commersoni Le Sueur. United States Bureau of Fisheries Bulletin 42:147-184. 
Van Oosten, J. 1923. The whitefishes (Coregonus clupeaformis). A study of the scales of whitefishes of known ages. Zoologica (New York) 2:381-412.

VAn OOsten, J. 1929. Life history of the lake herring (Leucichthys artedi Le Sueur) of Lake Huron as revealed by its scales with a critique of the scale method. United States Bureau of Fisheries Bulletin $44: 265-428$.
VAN OOSIEN, J. 1941. The age and growth of freshwater fishes. Pages 196-205 in A symposium on hydrobiology. University of Wisconsin Press, Madison, Wisconsin, USA.

Westrhelm, S. J. 1973. Age determination and growth of Pacific ocean perch (Sebastes alutus) in the northeast Pacific Ocean. Journal of the Fisheries Research Board of Canada 30:235-247. 